\title{
Damping of Torsional Vibrations in a Type-IV Wind Turbine Interfaced to a Grid-Forming Converter
}

\author{
Artur Avazov $^{1,2}$, Frédéric Colas ${ }^{1}$, Jef Beerten ${ }^{2}$, Xavier Guillaud ${ }^{1}$ \\ ${ }^{1}$ Univ. Lille, Arts et Metiers Institute of Technology, Centrale Lille, Junia, ULR 2697 - \\ L2EP - Laboratoire d'Electrotechnique et d'Electronique de Puissance, F-59000 \\ Lille, France \\ ${ }^{2}$ KU Leuven ESAT/ELECTA Research Group \& EnergyVille \\ Leuven \& Genk, Belgium \\ artur.avazov@centralelille.fr
}

\begin{abstract}
This paper introduces a Type-IV wind turbine interfaced to a grid-forming converter. In order to retain the stable operation of a wind turbine in the presence of a grid-forming control, the classical control of a back-to-back converter has to be modified. The modification of this control creates a strong link between a wind turbine and grid dynamics. From the grid side perspective, this link allows provision of the inertial response from a wind turbine during transient events. On the wind turbine side, this coupling causes the appearance of the torsional vibrations within the drivetrain structure. These vibrations are then propagated to the grid as power oscillations. As a result, there is a negative impact on the mechanical components of a wind turbine as well as on the power system operation. In this work, a solution is introduced in order to suppress the undesired vibrations by applying a damping technique to the control of a back-to-back converter combined with a grid-forming control. Based on the conducted analysis, the addition of a damping filter results in the mitigation of torsional vibrations.
\end{abstract}

Index Terms-damping, direct drive, inertial response, gridforming control, torsional vibrations, voltage source converter, Type-IV wind turbine

\section{INTRODUCTION}

According to [1], the amount of the newly commissioned wind power plants (WPPs) containing the most up-to-date wind turbines will be annually increasing by around $18 \%$ until 2030. Wind turbines are interfaced with the electrical grid via power electronic (PE) converters required to be synchronized with a stiff grid voltage by means of a phaselocked loop (PLL). These grid-following converters cannot operate independently without a stable grid voltage. Since the future power system is expected to be dominated by converter-interfaced generation, which will have the major role in ensuring the system stability [2], a relatively new converter control methodology known as a grid-forming control (GFC) has been developed [3], [4].

A grid-forming converter operates as a voltage source generating the fixed voltage and frequency at the output terminals based on the information from local measurements [5]. There is a large number of different ways to implement a GFC.

978-1-6654-3597-0/21/\$31.00 @2021 IEEE
Most of them are emulating the swing equation [6]-[8]. As a result, a GFC is capable of providing the inertial effect [9]. On top of that, the research in [10] has shown the possibility to combine a GFC with the primary frequency support. In combination, these features make a grid-forming converter able to demonstrate a behavior that is in a way similar to the one of a traditional synchronous machine (SM) [11].

When applied to Type-IV wind turbines, the transition from a grid-following to a grid-forming converter operation will also involve the need to reconsider the classical control of its back-to-back (B2B) converter. In order to keep stable power transmission and integrate a GFC, control modifications of such a B2B converter have been proposed in [12]-[14]. In these works, the impact of the converter control on the wind turbine and on the grid dynamics was not completely analyzed because a one-mass drivetrain model was used for the analysis.

In this article, a two-mass drivetrain model is taken into account, demonstrating the torsional vibrations induced in the drivetrain. These vibrations are a consequence of the use of a B2B converter with a modified control linking fast variations of the grid frequency with the electromagnetic torque of a generator. Concerning the impact of torsional vibrations, they can affect the lifetime of wind turbine components. Moreover, mechanical vibrations can be converted into electrical power oscillations interacting with power system modes. From a perspective of a system operator, it is highly undesirable [15]. Therefore, vibrations are usually damped through control actions of the machine-side converter [15]-[17]. To the authors' knowledge, such damping of torsional vibrations has not been implemented and analyzed before for the wind turbine interfaced to the grid with a grid-forming converter. Hence, it is considered as the main contribution of this paper.

The remainder of the paper is organized as follows. Section II describes the system and the model under study. It highlights the components of a wind turbine and its control. Also, it presents a GFC and the overall control configuration of the model. Section III is dedicated to the description of the utilized damping method. In Section IV the results from the application of the damping filter are presented. Finally, in Section V, the conclusion is given. 


\section{Modelling AND CONTROL OF THE WIND TURBINE INTERFACED TO A GRID-FORMING CONVERTER}

The system under study is shown in Fig. 1. It includes a direct-drive Type-IV wind turbine connected to an equivalent $\mathrm{AC}$ grid through a B2B converter. The B2B converter consists of a machine-side (MSC) and a grid-side converter (GSC).

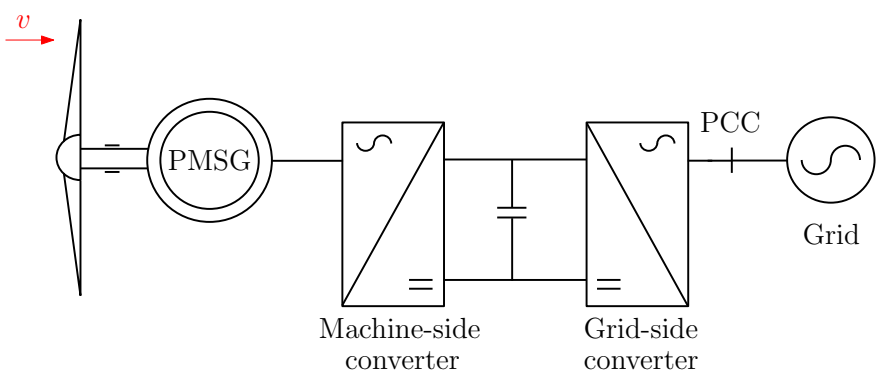

Fig. 1. The system under study.

\section{A. Model description}

The system model is presented in Fig. 2. The AC grid is set with a variable frequency implemented by adding a model of a simplified SM. It contains the governor, prime mover and the mechanical model with an equivalent inertia. The MSC and GSC are represented by average voltage source converters (VSCs). From Fig. 2, $p_{m s c}^{*}$ and $p_{g s c}^{*}$ are the instantaneous values of the active power reference for the MSC and GSC, $p_{p c c}$ is the instantaneous active power measured at the PCC, $\hat{\omega}_{g}$ is the grid frequency measured by PLL, $\theta_{g}$ is the grid voltage angle, $L_{f}, R_{f}$ and $L_{g}, R_{g}$ are the filter and the grid equivalent inductances and resistances, respectively.

\section{B. Wind turbine}

The wind turbine model includes a turbine, a two-mass drivetrain and a permanent-magnet synchronous generator (PMSG). The wind turbine is equipped with maximum power point tracking (MPPT) and pitch control.

- Turbine aerodynamics

The mechanical power, $P_{m, w t}$, captured by a wind turbine are found as:

$$
P_{m, w t}=0.5 \rho A C_{p}(\lambda, \beta) v_{w i n d}^{3}
$$

where $\rho$ is the air density, $A$ is the area swept by a wind turbine rotor, $C_{p}$ is the power coefficient, $\lambda$ is the tip-speed ratio, $\beta$ is the pitch angle, $v_{\text {wind }}$ is the wind speed.

\section{- Drivetrain}

To estimate the impact of the wind turbine dynamics on the grid, a two-mass drivetrain model is considered. It can be described with the motion equations:

$$
\begin{aligned}
2 H_{t} \frac{d \omega_{t}}{d t} & =T_{m}-k_{s} \theta-d_{s} \dot{\theta} \\
2 H_{g} \frac{d \omega_{g e n}}{d t} & =k_{s} \theta+d_{s} \dot{\theta}-T_{e m}
\end{aligned}
$$

$$
\frac{d T_{s h}}{d t}=k_{s} \dot{\theta}+d_{s} \ddot{\theta}
$$

$\theta=\int\left(\omega_{t}-\omega_{g e n}\right)$ is the shaft displacement, $H_{t}, H_{g}$ are inertia constants of a turbine and a generator, respectively, $T_{m}, T_{s h}, T_{e m}$ are the mechanical, shaft and electromagnetic torques, $k_{s}, d_{s}$ are the shaft stiffness and damping coefficient, and $\omega_{t}, \omega_{g e n}$ are the mechanical speed on the turbine and generator side.

\section{- Generator}

The mechanical power coming from the wind turbine is converted into electrical power by a PMSG whose model is described in a rotating d-q frame as:

$$
\begin{gathered}
\frac{d i_{s, d}}{d t}=\frac{1}{L_{s}}\left(v_{s, d}-R_{s} i_{s, d}+L_{s} \omega_{e l} i_{s, q}\right) \\
\frac{d i_{s, q}}{d t}=\frac{1}{L_{s}}\left(v_{s, q}-R_{s} i_{s, q}-L_{s} \omega_{e l} i_{s, d}-\psi_{m} \omega_{e l}\right) \\
T_{e m}=\frac{3}{2} \psi_{m} \omega_{e l} i_{s, q}
\end{gathered}
$$

where $i_{s, d}, i_{s, q}$ and $v_{s, d}, v_{s, q}$ are the d-q stator currents and voltages, $L_{s}, R_{s}$ are the stator inductance and resistance, $\omega_{e l}=$ $p \omega_{\text {gen }}$ is the generator electrical speed (with $p$ the number of pole pairs), and $\psi_{m}$ is the flux linkage of the permanent magnet.

The generator control is implemented using field oriented current control, and the voltage references are derived from the current loops so that:

$$
\begin{gathered}
v_{s, d}^{*}=\left(K_{p}+\frac{K_{i}}{s}\right)\left(i_{s, d}^{*}-i_{s, d}\right)-L_{s} \omega_{e l} i_{s, q} \\
v_{s, q}^{*}=\left(K_{p}+\frac{K_{i}}{s}\right)\left(i_{s, q}^{*}-i_{s, q}\right)+L_{s} \omega_{e l} i_{s, d}+\psi_{m} \omega_{e l}
\end{gathered}
$$

\section{- MPPT}

When a wind turbine operates at the partial load, the extracted active power corresponds to the optimal power curve:

$$
P_{m p p t}^{*}\left(\omega_{g e n}\right)=0.5 \rho A C_{p, o p t}\left(\frac{\omega_{g e n} R_{w t}}{\lambda_{o p t}}\right)^{3}
$$

- Pitch control

The pitch angle is controlled with a gain-scheduling technique compensating the variations of the aerodynamic characteristics of a turbine [18]. The pitch control is shown in Fig. 3.

\section{Grid-forming control}

As mentioned in the introduction, a grid-forming converter can form the voltage and the frequency at the output terminals. To emulate the swing equation, a GFC is modeled with a virtual synchronous machine (VSM) [6]. Its per-unit differential equation is given as:

$$
2 H_{v s c} \frac{d \omega_{m}}{d t}=p_{g s c}^{*}-p_{p c c}-K_{v s c}\left(-\hat{\omega}_{g}+\omega_{m}\right)
$$

where $H_{v s c}$ and $K_{v s c}$ are the inertia constant and damping coefficient, $\omega_{m}$ is the converter frequency. 




Fig. 2. System model.

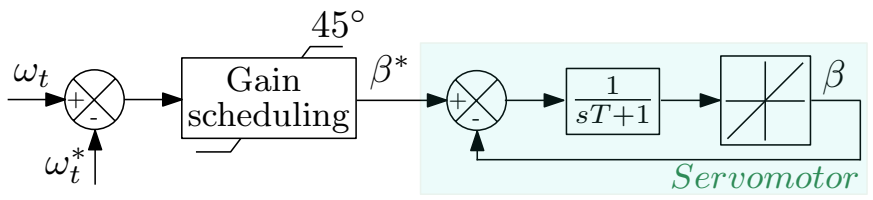

Fig. 3. Pitch control.

In steady state, $\omega_{m}=\hat{\omega}_{g}$, then, it can be deduced from (11) that $p_{p c c}=p_{g s c}^{*}$. During a frequency transient, $\omega_{m} \neq \hat{\omega}_{g}$, the active power is not equal to the power reference, $p_{p c c} \neq p_{g s c}^{*}$. This is linked with the inertial effect of a GFC.

The dynamic implementation of the GFC is shown in Fig. 4, where $R_{v}$ is the damping resistor and $\omega_{f}$ is the cut-off frequency of a low-pass filter.

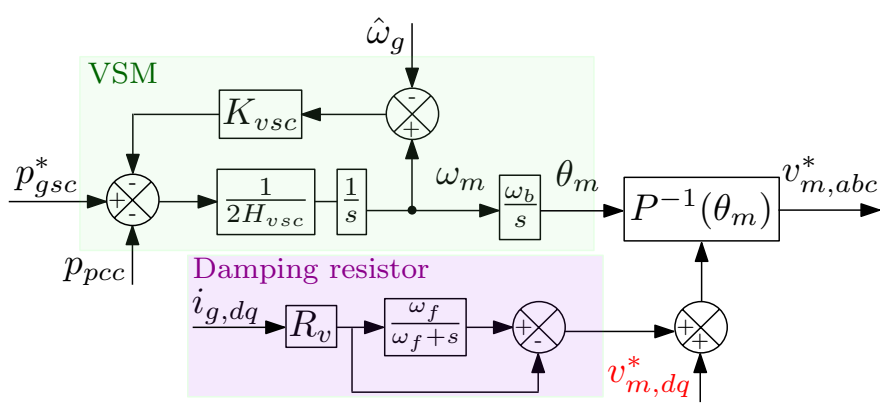

Fig. 4. Grid-forming control.

\section{Overall control configuration}

The stable operation of a $\mathrm{B} 2 \mathrm{~B}$ converter depends on the power balance between both sides of the DC bus capacitor. Thus, the MSC and GSC are to be controlled in a proper way to maintain the balance. In order to maintain DC bus voltage and integrate a GFC to the control of a B2B converter, the choice of the optimal control strategy has been described in [19]. According to this strategy, the DC bus voltage is controlled by the MSC, while the GSC controls the power transmission to the grid and ensures GFC capabilities. With this control, there is a link between a wind turbine and grid dynamics created by the decoupling of the GFC from the DC bus voltage control. Therefore, this strategy performs the power transmission from a wind turbine, maintains a stable DC bus voltage and ensures GFC capabilities at the same time. The overall control configuration is shown in Fig. 2.

\section{DAMPING OF TORSIONAL VIBRATIONS}

From the model with the chosen control depicted in Fig. 2, it is possible to determine that the grid frequency variation will result in inertial response from the GSC and, consequently, the fast reaction of the DC bus voltage control which will rapidly increase the generator electromagnetic torque to maintain the DC bus voltage. The increase of the electromagnetic torque is much faster than it would be in case of a classical B2B converter control. So, the swift variations of the electromagnetic torque can excite drivetrain oscillatory modes and induce these unwanted torsional vibrations to propagate within the wind turbine structure and to eventually be reflected on the grid side as power oscillations. Torsional vibrations impose large stresses on turbine components and reduce their lifetime. Furthermore, induced power oscillations can lead to undesired dynamic interaction between the wind turbine and the grid.

Torsional vibrations can be damped using different methods [15]-[17]. The main idea is typically to impact the electromagnetic torque reference with the filtered oscillation component of the rotational speed. This approach is utilized in this paper and implemented by adding a high-pass filtered measurement of the rotational speed on the generator side to the torque 
reference to cancel any action in case of a steady state or slow speed variations. Its transfer function can be expressed as:

$$
H_{d}(s)=\frac{s K_{d}}{s T_{d}+1}=\frac{\omega_{g e n}}{T_{e m}^{*}}
$$

where $K_{d}$ is a damping gain and $T_{d}$ is a filter time constant which can be chosen based on the frequency of the vibrations to be damped.

\section{DAMPING APPLICATION}

The damping filter is applied to the model of a Type-IV wind turbine shown in Fig. 2. The damping block is presented in detail in Fig. 5. It includes a high-pass filter as well as the conversion steps needed to obtain the q-axis current reference.

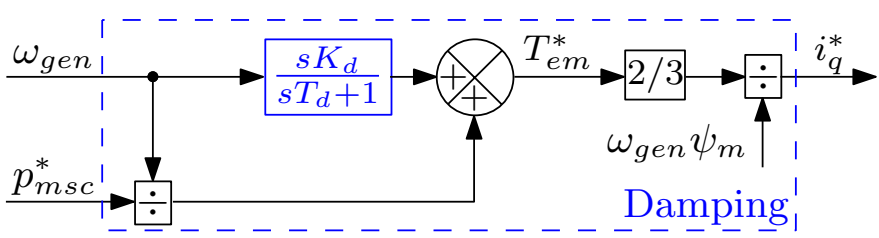

Fig. 5. Damping block description.

The parameters of the grid, wind turbine and controllers are summarized in Tables I to III. The $5 \mathrm{MW}$ wind turbine operates near the nominal point with the constant wind speed of 11.4 $\mathrm{m} / \mathrm{s}$. To demonstrate the effect of the included damping, the event of the grid frequency variation is simulated by connecting a $1 \mathrm{MW}$ load to the grid bus at $50 \mathrm{~s}$. The results in Fig. 6 and 7 are obtained for three cases: 1) no damping, 2) damping, $K_{d}=1,3$ ) damping, $K_{d}=2$.

The process leading to the excitation of torsional vibrations can be understood as follows. As seen in Fig. 6(a)-(b), once the grid frequency starts reducing, the GSC provides the inertial response by supplying the additional active power. It is followed with a power imbalance on the DC side and reduction of the DC bus voltage as shown in Fig. 6(c). The electromagnetic torque, which has been rapidly increased by the DC bus voltage control, slows down the rotational speed of the wind turbine and excites the torsional vibrations in the drivetrain as highlighted in Fig. 7(a)-(b). These vibrations are then reflected on the DC and $\mathrm{AC}$ side as is clear from the oscillations in DC bus voltage and active power in Fig. 6(b)(c).

It is demonstrated in Fig. 7(a)-(b), how the applied damping with a damping gain, $K_{d}=1$, allows mitigating the vibrations on the generator and turbine side of the wind turbine. Then, Fig. 6(a)-(c) illustrate that less oscillations are propagated on the $\mathrm{DC}$ and $\mathrm{AC}$ side. In case of the increased damping gain, $K_{d}=2$, the vibrations as well as the oscillations are better damped. The only disadvantage of the analyzed damping method is the increased amplitude of the DC bus voltage variation during frequency transient indicated in Fig. 6(c).

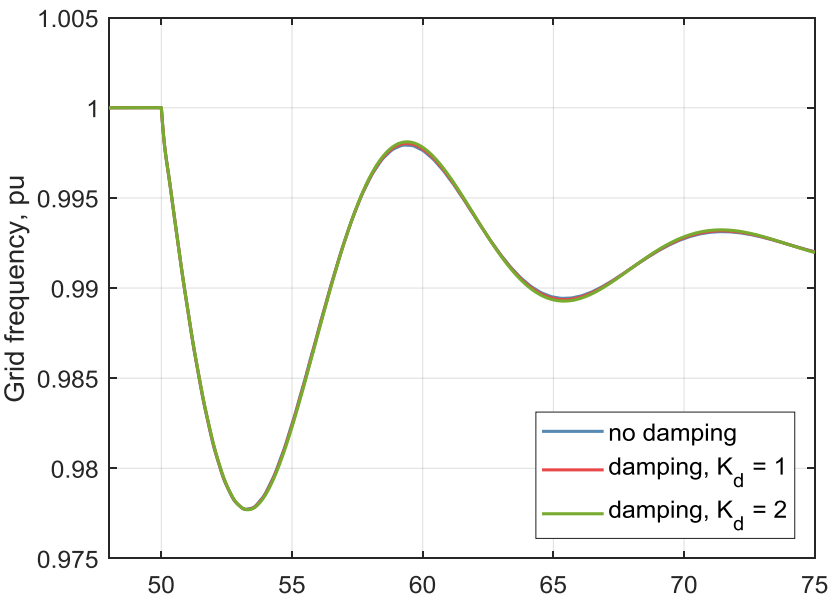

a)
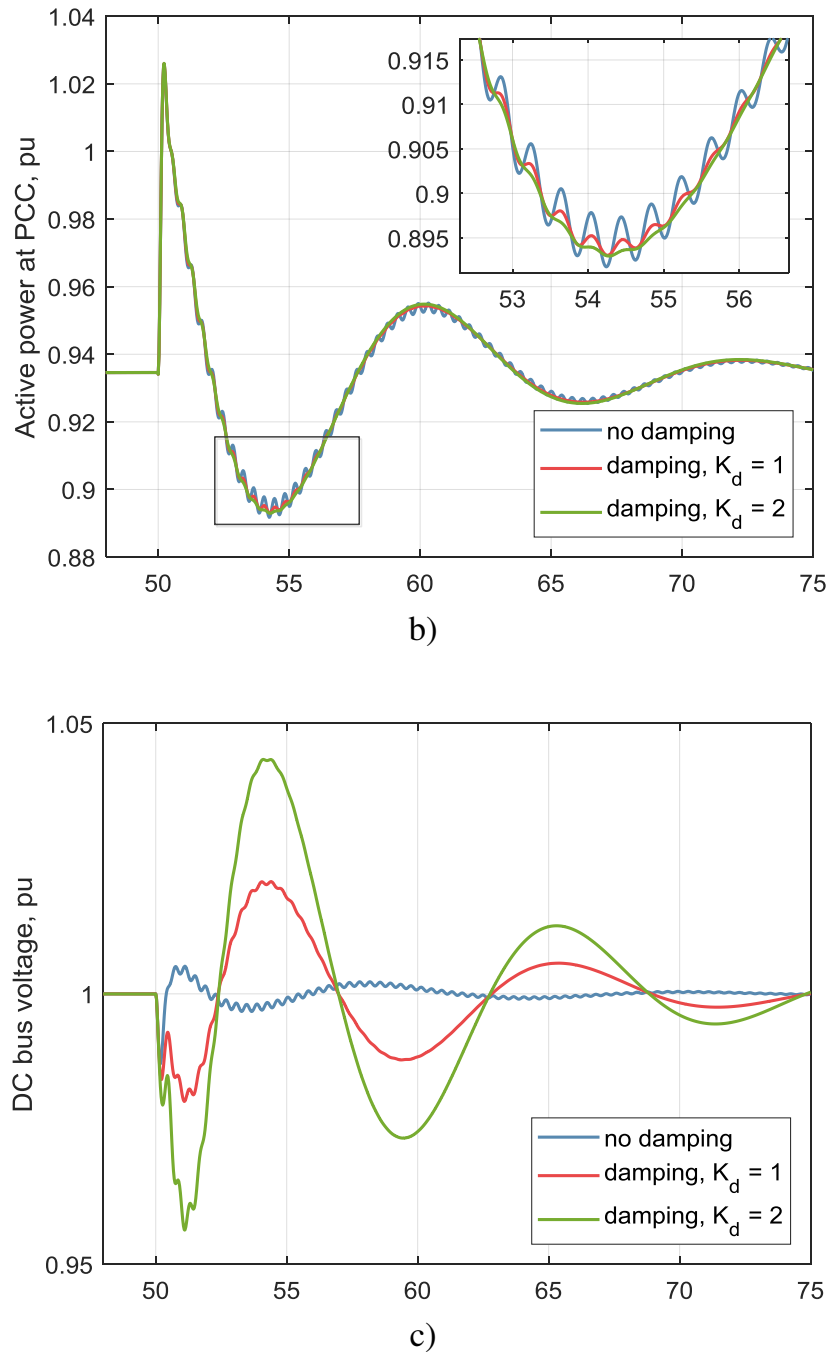

Fig. 6. Simulation results: a) grid frequency, b) active power at the PCC, c) DC bus voltage. 


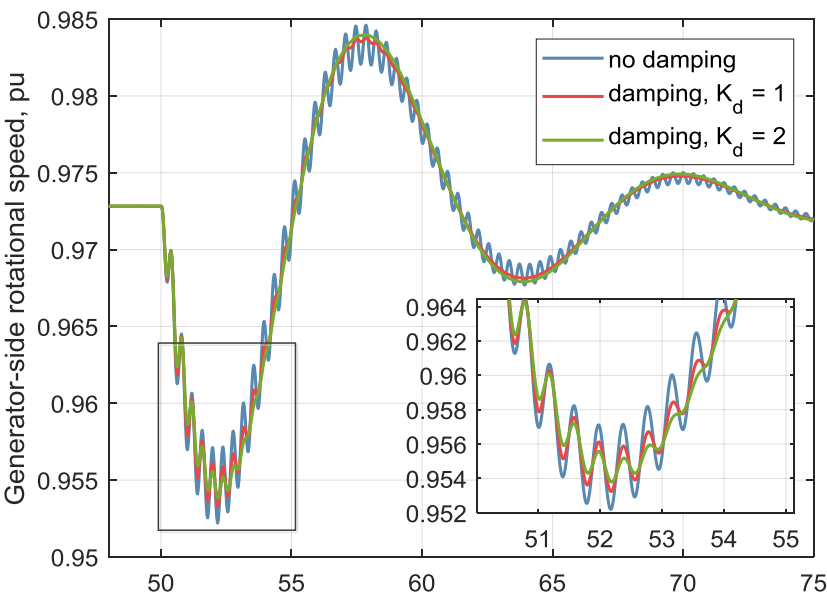

a)

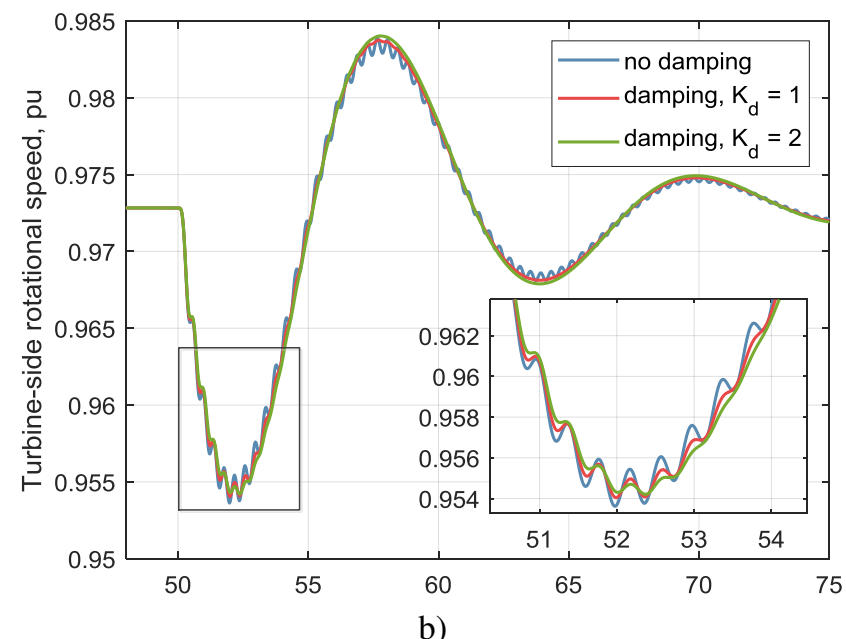

Fig. 7. Simulation results: a) rotational speed on the generator side, b) rotational speed on the turbine side.

\section{CONClusion}

The research dedicated to the analysis of a Type-IV wind turbine interfaced to the electrical grid with a grid-forming converter in this paper has demonstrated how the control of a B2B converter has to be configured in order to combine the operation of a wind turbine with the useful functionalities of a GFC. It was shown that the utilized control creates a strong coupling between the electromagnetic torque of a wind turbine's generator and grid dynamics. As a result, variations in grid frequency can impose a severe impact on the mechanical components of a wind turbine. From simulation studies it was illustrated how a rapid change of the electromagnetic torque can induce torsional vibrations in a drivetrain during the frequency transient. Therefore, a damping filter was applied to the control of a back-to-back converter in order to present a possibility to mitigate the unwanted vibrations. The only identified drawback of the applied damping method is the amplitude increase of the DC bus voltage variations during a transient period. This could be mitigated by increasing the size of DC side capacitor, its nominal voltage or adding additional storage.

TABLE I

PARAMETERS OF THE GRID

\begin{tabular}{l|l}
\hline Parameter & Value \\
\hline$S_{g}, U_{g}, S C R$ & $5 \mathrm{MW}, 690 \mathrm{~V}, 5$ \\
\hline$R_{g}, L_{g}, R_{f}, L_{f}$ & $0.02 \mathrm{pu}, 0.2 \mathrm{pu}, 0.005 \mathrm{pu}, 0.15 \mathrm{pu}$ \\
\hline$T_{N}, T_{D}, R_{s}, H_{e q}$ & $1,6,4 \%, 5 \mathrm{~s}$ \\
\hline
\end{tabular}

TABLE II

PARAMETERS OF WIND TURBINE AND PMSG

\begin{tabular}{l|l}
\hline Parameter & Value \\
\hline & Wind turbine \\
\hline$P_{w t}, \omega_{t, n o m}$ & $5 \mathrm{MW}, 1.27 \mathrm{rad} / \mathrm{s}$ \\
\hline$R_{w t}, \lambda_{\text {opt }}, C_{p, \text { opt }}$ & $63 \mathrm{~m}, 7,0.44$ \\
\hline$k_{s}, d_{s}, H_{t}$ & $280 \mathrm{pu}, 1 \mathrm{pu}, 1.93 \mathrm{~s}$ \\
\hline \multicolumn{2}{|c}{ PMSG } \\
\hline$P_{\text {gen }}, U_{s}, \omega_{\text {elec }}, H_{g}$ & $5 \mathrm{MW}, 690 \mathrm{~V}, 61 \mathrm{rad} / \mathrm{s}, 0.8 \mathrm{~s}$ \\
\hline$R_{s}, L_{s}, \psi_{m}$ & $2.45 \mathrm{~m} \Omega, 4 \mathrm{mH}, 5.84 \mathrm{~Wb}$ \\
\hline
\end{tabular}

TABLE III

PARAMETERS OF CONTROLLERS

\begin{tabular}{l|l}
\hline Parameter & Value \\
\hline$H_{v s c}, K_{v s c}, R_{v}, \omega_{f}$ & $3.5 \mathrm{~s}, 233 \mathrm{pu}, 0.09 \mathrm{pu}, 60 \mathrm{rad} / \mathrm{s}$ \\
\hline$\tau_{p l l}, \xi_{p l l}, K_{p, p l l}, K_{i, p l l}$ & $10 \mathrm{~ms}, 0.707,1.9,0.0033$ \\
\hline$\tau_{d c}, \xi_{d c}, K_{p, d c}, K_{i, d c}$ & $2 \mathrm{~s}, 0.707,0.18,0.19$ \\
\hline$\tau_{p i t c h}, \xi_{p i t c h}, K_{p, p i t c h}, K_{i, p i t c h}$ & $4 \mathrm{~s}, 0.707$, (gain scheduling) \\
\hline
\end{tabular}

\section{ACKNOWLEDGMENT}

This work is financially supported by the foundation I-SITE Université Lille Nord - Europe in a joint PhD collaboration with KU Leuven.

\section{REFERENCES}

[1] J. Lee, F. Zhao, A. Dutton, B. Backwell, L. Qiao, S. Lim, A. Lathigaralead, and W. Liang, "Global offshore wind report 2020," Brussels, 2020. Accessed: Oct. 07, 2020. [Online]. Available: www.gwec.net.

[2] G. Denis, T. Prevost, M. S. Debry, F. Xavier, X. Guillaud, and A. Menze, "The migrate project: The challenges of operating a transmission grid with only inverter-based generation. A grid-forming control improvement with transient current-limiting control," in IET Renewable Power Generation, Apr. 2018, vol. 12, no. 5, pp. 523-529.

[3] J. Rocabert, A. Luna, F. Blaabjerg, and P. Rodríguez, "Control of power converters in AC microgrids," IEEE Transactions on Power Electronics, vol. 27, no. 11, pp. 4734-4749, 2012.

[4] P. Unruh, M. Nuschke, P. Strauß, and F. Welck, "Overview on gridforming inverter control methods," Energies, vol. 13, no. 10, May 2020.

[5] T. Qoria, Q. Cossart, C. Li, X. Guillaud, F. Colas, F. Gruson, and X. Kestelyn, "WP3 - Control and Operation of a Grid with 100\% ConverterBased Devices. Deliverable 3.2: Local control and simulation tools for large transmission systems," 2019. Accessed: Apr. 15, 2020. [Online]. Available: https://www.h2020-migrate.eu/.

[6] S. D'Arco, J. A. Suul, and O. B. Fosso, ”A Virtual Synchronous Machine implementation for distributed control of power converters in SmartGrids," Electric Power Systems Research, vol. 122, pp. 180-197, May 2015. 
[7] T. Qoria, F. Gruson, F. Colas, G. Denis, T. Prevost, and X. Guillaud, "Inertia effect and load sharing capability of grid forming converters connected to a transmission grid," in IET Conference Publications, 2019, vol. 2019.

[8] E. Rokrok, T. Qoria, A. Bruyere, B. Francois, and X. Guillaud, "Effect of Using PLL-Based Grid-Forming Control on Active Power Dynamics under Various SCR," in IECON Proceedings (Industrial Electronics Conference), Oct. 2019, vol. 2019-October, pp. 4799-4804.

[9] M. Paolone, T. Gaunt, X. Guillaud, M. Liserre, S. Meliopoulos, A. Monti, T. Van Cutsem, V. Vittal, and C. Vournas, "Fundamentals of power systems modelling in the presence of converter-interfaced generation," Electric Power Systems Research, vol. 189, p. 106811, Dec. 2020.

[10] E. Rokrok, T. Qoria, A. Bruyere, B. Francois, and X. Guillaud, "Classification and dynamic assessment of droop-based grid-forming control schemes: Application in HVDC systems," Electric Power Systems Research, Dec. 2020.

[11] U. Tamrakar, D. Shrestha, M. Maharjan, B. Bhattarai, T. Hansen, and R. Tonkoski, "Virtual Inertia: Current Trends and Future Directions," Applied Sciences, vol. 7, no. 7, p. 654, Jun. 2017.

[12] Daniel Duckwitz, "Power system inertia: Derivation of requirements and comparison of inertia emulation methods for converter-based power plants," Ph.D dissertation, Dept. Elec. Eng. and Comp. Science, University of Kassel, Kassel, 2019.

[13] L. Shang, J. Hu, X. Yuan, and Y. Chi, "Understanding inertial response of variable-speed wind turbines by defined internal potential vector," Energies, vol. 10, no. 1, 2017.

[14] K. Gunther and C. Sourkounis, "Investigation of Virtual Synchronous Machine Control for the Grid-Side Converter of Wind Turbines with Permanently Excited Synchronous Generator," in IECON Proceedings (Industrial Electronics Conference), Oct. 2019, vol. 2019-Octob, pp. 2395-2401.

[15] J. Licari, C. E. Ugalde-Loo, J. B. Ekanayake, and N. Jenkins, "Damping of torsional vibrations in a variable-speed wind turbine," IEEE Transactions on Energy Conversion, vol. 28, no. 1, pp. 172-180, 2013.

[16] F. Fateh, W. N. White, and D. Gruenbacher, "Torsional vibrations in the drivetrain of DFIG- And PMG-based wind turbines - Comparison and mitigation," in ASME 2015 Dynamic Systems and Control Conference, DSCC 2015, 2015, vol. 2.

[17] A. D. Hansen and G. Michalke, "Modelling and control of variable-speed multi-pole permanent magnet synchronous generator wind turbine," Wind Energy, vol. 11, no. 5, pp. 537-554, Sep. 2008.

[18] C. Tibaldi, L. C. Henriksen, M. H. Hansen, and C. Bak, "Effects of gain-scheduling methods in a classical wind turbine controller on wind turbine aeroservoelastic modes and loads," in 32nd ASME Wind Energy Symposium, 2014.

[19] A. Avazov, F. Colas, J. Beerten, and X. Guillaud, "Influence of the frequency support provided by a grid-forming control-based wind turbine on the loading of its mechanical system," unpublished, presented in 19th Wind Integration Workshop, 2020. 